www.jik.ub.ac.id

Doi 10.21776/ub.jik.2020.008.01.2

P-ISSN: 2088-6012 E-ISSN: 2598-8492

Research article

\title{
THE RELATIONSHIP OF RESILIENCE AND QUALITY OF LIFE PATIENT WITH CHRONIC KIDNEY DISEASE WHO UNDERGOING HAEMODIALYSIS IN RASYDA KIDNEY HOSPITAL MEDAN
}

Jagentar Pane ${ }^{1^{*}}$, Ice Septriani Saragih ${ }^{1}$

Afiliasi

1. STIKes Santa Elisabeth Medan

Dikirim 9 Maret 2020

Direvisi 19 Juni 2020

Diterima 23 Juni 2020

Dipublikasikan 30 juni 2020

*Korespondensi

Email :

jagentarp@gmail.com

\begin{abstract}
ABSTRAK
Salah satu pengobatan penyakitginjal kronis stadium akhir adalah dengan hemodialisis. Terjadinya gangguan pada fungsi tubuh dan psikologis pasien hemodialisis menyebabkan pasien harus melakukan penyesuaian diri (resiliensi) secara terus menerus selama sisa hidupnya. Perasaan stress, putus asa dan ketidakberdayaan sering dihadapi penderita dapat mempengaruhi kualitas hidupnya. Penelitian ini bertujuan untuk mengetahui hubungan resiliensi dengan kualitas hidup pasien penyakit gagal ginjal yang menjalani tindakan hemodialisis di Rumah Sakit Khusus Ginjal Rasyda Medan. Penelitian ini merupakan jenis penelitian deskriptif korelatif dengan menggunakan rancangan cross sectional. Jumlah sampel dalam penelitian ini adalah 117 orang dimana pengambilan sampel dengan purposive sampling. Hasil penelitian menunjukkan bahwa pasien penyakit ginjal kronis yang menjalani hemodialisis di Rumah Sakit Khusus Ginjal Rasyida mayoritas (85,5\%) memiliki resiliensi yang tinggi dan memiliki kualitas hidup yang cukup $(66,7 \%)$. Hasil penelitian juga menunjukkan bahwa ada hubungan resiliensi dengan kualitas hidup pasien penyakit ginjal kronis yang menjalani hemodialisis di Rumah Sakit Khusus Ginjal Rasyida ( $p=0,001, \alpha<$ $0,005)$. Peneliti menyarankan agar penelitian selanjutnya melakukan penelitian tentang faktor-faktor yang mempengaruhi resiliensi dan kualitas hidup pasien gagal ginjal kronis yang menjalani hemodialisis.
\end{abstract}

Kata Kunci : kualitas hidup, resiliensi, penyakit ginjal kronis

\begin{abstract}
Haemodialysis can cause disorders in patient's body function and psychological that can make patient have to adaptation continuously for the rest of patient's life. Patients who suffering chronic diseases like chronic kidney disease feel unable to face, undergo, and accept the illness, so there is a need for resilience. Feelings stressed, hopelessness and helplessness often faced by sufferers Chronic kidney disease can affect his/her quality of life. This study aimed to determine the relationship of resilience and quality of life of patients with chronic kidney disease who undergoing haemodialysis at the Rasyda Kidney Hospital. This study was a descriptive correlative type of research using cross sectional design and the number of samples were 117 people with purposive sampling technique. The results showed that patients with chronic kidney disease who underwent haemodialysis at the majority Rasyida Kidney Special Hospital (85.5\%) had high resilience and had an adequate quality of life (66.7\%). The results also showed that there was a relationship of resilience with the quality of life of patients with chronic kidney disease undergoing haemodialysis at the Rasyida Kidney Special Hospital ( $p=0.001, \alpha$ $<0.005)$. Researchers suggest that future studies conduct research on the factors that affect resilience and quality of life of patients with chronic kidney disease undergoing haemodialysis.
\end{abstract}

Keywords : quality of life, resilience, chronic kidney disease

Sitasi jurnal :

Pane J \& Saragih IC. 2020. The Relationship Of Resilience And Quality Of Life Patient With Chronic Kidney Disease Who Undergoing Haemodialysis In Rasyda Kidney Hospital Medan. Jurnal Ilmu Keperawatan Volume 8(1): 10-14. Doi 10.21776/ub.jik.2020.008.01.2 


\section{PENDAHULUAN}

Penyakit ginjal kronik sudah merupakan masalah kesehatan masyarakat di seluruh dunia. Laporan dari Indonesian Renal Registry (IRR) menyebutkan pertumbuhan jumlah penderita gagal ginjal terus meningkat dari tahun ke tahun. Jumlah pasien baru yang menjalani terapi hemodialisis di tahun 2015 adalah 2105 pasien dan pasien aktif sejumlah 30554 pasien. Distribusi usia pada tahun 2015 terbanyak adalah antara usia 45-54 tahun dan 55-64 tahun. Pada tahun 2015 tercatat 1243 pasien mengalami kematian dengan lama hidup dengan hemodialisis antara 1 sampai 317 bulan. Pasien yang menjalani hemodialisis lama hidup terbanyak adalah $6-12$ bulan tetapi lama hidup tertinggi bisamencapai 317 bulan (8th Report of Indonesian Renal Registry, 2016 dalam Ramadhan, et al, 2018). Pasien dengan penyakit ginjal menjalani proses hemodialisis 1-3 kali seminggu dan setiap kalinya memerlukan waktu 2-5 jam, kegiatan ini akan berlangsung terus-menerus sepanjang hidupnya (Smeltzer, S. C., \& Bare, B. G, 2010).

Pengobatan bagi penderita penyakit ginjal kronik tahap akhir, dilakukan dengan pemberian terapi dialysis seperti hemodialisis atau transplantasi ginjal yang bertujuan untuk mempertahankan kualitas hidup pasien (Smeltzer, S. C., \& Bare, B. G, 2010). Terjadinya gangguan pada fungsi tubuh pasien hemodialisis, menyebabkan pasien harus melakukan penyesuaian diri secara terus menerus selama sisa hidupnya (Arosa, 2014). Bagi pasien hemodialisis, penyesuaian ini mencakup keterbatasan dalam memanfaatkan kemampuan fisik dan motorik, penyesuaian terhadap perubahan fisik dan polahidup, ketergantungan secara fisik dan ekonomi pada orang lain serta ketergantungan pada mesin dialisa selama sisa hidup. Keadaan seperti ini dapat menimbulkan perasaan tertekan bahkan dapat menimbulkan gangguan-gangguan mental seperti depresi (Oktaviana, 2010). Hasil penelitian yang dilakukan oleh Ibrahim et al (2009) menunjukkan bahwa $57.2 \%$ pasien yang menjalani hemodialisis mempersepsikan kualitas hidupnya pada tingkat rendah dan $42,9 \%$ pada tingkat tinggi.

Penelitian lain yang dilakukan oleh Triwahyuni (2012) di Rumah Sakit Advent Bandung menjelaskan bahwa pasien yang menderita penyakit kronis merasa tidak mampu dalam menghadapi, menjalani, serta menerima penyakityang diderita sehingga perluadanya penyesuaian diri (resiliensi). Resiliensi dilakukan dengan upaya mendorong pasien untuk tetap berjuang memenuhi kebutuhannya, bahagia dan berkembang menjadi individu yang lebih kuat, lebih bijak dan lebih menghargai kehidupan (Grief, 2005 dalam Wijayani MR, 2008). Resiliensi pasien yang menjalani pengobatan di rumah sakit merupakan suatu hal yang perlu dikaji untuk mencapai keseimbangan kembali akibat perubahan-perubahan yang dialaminya. Perasaan putus asa dan ketidakberdayaan sering dihadapi penderita karena berbagai pengobatan tidak dapat membantunya sembuh dari penyakit kronis. Keadaan stress berat juga dapat muncul akibat ketidaksiapan tubuh menerima perubahan dan tuntutan kehidupan (Sarafino, 2006). Penelitian yang dilakukan Iliescu dan Cotoi (2013) mengatakan bahwa diagnosa medis serta lingkungan rumah sakit juga dapat mempengaruhi psikis pasien berupa depresi, cemas, khawatir atau kombinasi antara semuanya jika individu tidak mampu melakukan resiliensi. Kemampuan resiliensi individu dengan penyakit kronis perlu diperhatikan karena stres yang berkepanjangan berdampak pada depresi, yang selanjutnya juga akan berdampak pada fungsi fisiologis tubuh (Sukadiyanto, 2010).

Secara umum, resiliensi ditandai oleh sejumlah karakteristik, yaitu: adanya kemampuan dalam menghadapi kesulitan, ketangguhan dalam menghadapi stres ataupun bangkit dari trauma yang dialami (Utami, 2017). Hasil penelitian yang dilakukan oleh Duncan et al (2005), menyatakan bahwa resiliensi mencakup keberadaan sejumlah kemampuan, karakteristik maupun berbagai kondisi individu yang tidak bertujuan untuk menghilangkan resiko, akan tetapi lebih pada upaya untuk mampu menghadapi hal-hal yang berpotensi memunculkan krisis dengan cara-cara yang positif. Bagi pasien hemodialisis yang resilien, resiliensi membuat hidupnya menjadi lebih kuat. Resiliensi akan membuat seseorang berhasil menyesuaikan diri dalam berhadapan dengan kondisikondisi yang tidak menyenangkan, perubahan gaya hidup yang timbul akibat terapi hemodialisis yang dijalani dan bahkan berbagai tekanan yang hebat (Halawati \& Kusuma, 2017)

Kondisi yang dialami oleh pasien gagal ginjal kronik yang menjalani hemodialisis ini dapat membawa ke keadaan kurang resiliensi, yaitu keadaan dimana seorang individu akan mudah merasa putus 
asa, kurang mampu beradaptasi dalam menghadapi perubahan yang diakibatkan oleh penyakitnya, menyalahkan orang lain, diri sendiri bahkan Tuhan YME atas penyakit yang diderita dan mungkin akan mempengaruhi kualias hidupnya (Andaryati, 2018).

Berdasarkan latar belakang diatas, penulis tertarik untuk mengetahui hubungan resiliensi dengan kualitas hidup pasien penyakit Ginjal Kronik yang menjalani tindakan hemodialisis di Rumah Sakit Khusus Ginjal Rasyda Medan

\section{METODE}

Penelitian ini merupakan jenis penelitian deskriptif korelatif dengan menggunakan rancangan Cross Sectional. Jumlah sampel dalam penelitian ini adalah 117 orang dengan teknik pengambilan sampel purposive sampling. Kriteria inklusi penelitian ini adalah pasien yang menjalani tindakan hemodialisa, bersedia menjadi responden, dapat membaca dan kooperatif. Peneliti menggunakan alat ukur 14 item Resilience Scale (RS-14) yang disusun oleh Wagnild dan Young dan Instrumen untuk mengukur kualitas hidup, peneliti menggunakan lembar kuesioner baku dari WHO yang disebut World Health Organization Quality Of Life (WHOQOL). Penelitian ini dilakukan pada bulan Desember 2019- Januari 2020 di Rumah Sakit Khusus Ginjal Rasyda Medan. Analisa data yang digunakan adalah analisa univariat dan bivariat. Analisis bivariat yang digunakan adalah uji Chi-square.

\section{HASIL}

\section{Resiliensi}

Hasil penelitian menunjukkan bahwa pasien penyakit ginjal kronis yang menjalani hemodialisis di Rumah Sakit Khusus Ginjal Rasyida mayoritas (85,5\%) memiliki resiliensi yang tinggi. Distribusi frekuensi resiliensi dapat dilihat pada table dibawah

Tabel 1. Distribusi frekuensi resiliensi

\begin{tabular}{lcc}
\hline \multicolumn{1}{c}{ Data } & Frekuen si (f) & (\%) \\
\hline Resiliensi rendah & 2 & 1,7 \\
Resiliensi sedang & 8 & 6,8 \\
Resiliensi tinggi & 100 & 85,5 \\
Resiliensi sangat tinggi & 7 & 6,0 \\
Jumlah & 117 & 100 \\
\hline
\end{tabular}

Sumber: data primer yang diolah

\section{Kualitas Hidup}

Hasil penelitian menunjukkan bahwa pasien gagal ginjal kronis yang menjalani hemodialisa di Rumah Sakit Khusus Ginjal Rasyida lebih dari setengah jumlah responden $(66,7 \%)$ memiliki kualitas hidup yang cukup. Distribusi frekuensi kualitas hidup dapat dilihat pada tabel di bawah.

Tabel 2. Distribusi frekuensi kualitas hidup

\begin{tabular}{lcc}
\hline \multicolumn{1}{c}{ Data } & Frekuensi (f) & (\%) \\
\hline $\begin{array}{l}\text { Kualitas } \\
\text { hidup kurang }\end{array}$ & 13 & 11,1 \\
$\begin{array}{l}\text { Kualitas } \\
\text { hidup cukup }\end{array}$ & 78 & 66,7 \\
$\begin{array}{l}\text { Kualitas } \\
\text { hidup baik }\end{array}$ & 26 & 22,2 \\
Jumlah & 117 & 100 \\
\hline
\end{tabular}

Sumber: data primer yang diolah

\section{Hubungan Resiliensi dengan Kualitas Hidup}

Hasil penelitian menunjukkan bahwa ada hubungan antara Resiliensi dengan Kualitas Hidup $(\alpha=0,001)$. Distribusi hubungan resiliensi dan kualitas hidup dapat dilihat pada tabel di bawah.

\section{Tabel 3. Hubungan resiliensi dan kualitas hidup}

\begin{tabular}{lc}
\hline Data & Nilai p (uji chi-square) \\
\hline Resiliensi & \\
Kualitas hidup & 0,000 \\
\hline
\end{tabular}

Sumber: Data yang diolah pribadi

\section{PEMBAHASAN}

\section{Resiliensi}

Resiliensi mempunyai arti sebagai stamina emosional dan digunakan untuk menjelaskan orang yang menunjukan keberanian dan kemampuan beradaptasi pada situasi hidup yang sulit (Wagnild \& Young, 2010). Hasil penelitian ini sejalan dengan penelitian lain yang dilakukan oleh Nurhasanah (2017) yang menemukan bahwa Resiliensi pasien gagal ginjal diketahui sebagian besar memiliki resiliensi sedang yaitu sebanyak 44 pasien (70\%) Menurut peneliti, responden sebernarnya sudah cukup mampu dan cukup memiliki resiliensi dalam menjalankan hemodialisa.

Hasil penelitian menunjukkan bahwa sebanyak 100 orang responden memiliki resiliensi yang tinggi. Responden memiliki kemampuan untuk bertahan pada 
situasi yang sulit dan mampu bangkit dari keterpurukan dalam waktu yang singkat. Hal tersebut menunjukkan bahwa individu mampu mengembalikan keadaan dan situasi negative seperti sediakala serta mampu mamdiri tanpa mengandalkan orang lain. Tingkat resiliensi yang tinggi pada seseorang dapat memberikan manfaat terhadap perilaku pengontrolan diet sehat yang efektif (Pane, 2014). Individu yang resilien disebut sebagai individu yang mampu menggunakan koping yang berfokus pada masalah ketika menghadapi situasi yang sulit serta memiliki sumbe koping yang memfasilitasi untuk mengatasi kesulitan, bertahan dalam keadaan penuh tekanan dan bangkit mengatasi ketidakberuntungan (Wagnild, 2010).

\section{Kualitas hidup}

WHO dalam WHOQOL (World Health Organization Quality of Life, 2010) mendefenisikan kualitas hidup sebagai gambaran atau model yang bertujuan untuk menggambarkan sudut pandang seseorang dengan berbagai macam istilah terhadap dimensi kehidupan yang terkait dengan tujuan, harapan, standart dan juga perhatian. Hasil penelitian menunjukkan bahwa ada hubungan antara Resiliensi dengan Kualitas Hidup $(\alpha=0,001)$. Hasil ini didukung oleh penelitian yang dilakukan oleh Rachmawati, dkk (2019) yang menjelaskan bahwa berdasarkan hasil uji regresi ditemukan resiliensi psikologis memiliki peran terhadap seluruh dimensi kualitas hidup yang terkait dengan kesehatan. Penelitian lain yang dilakukan oleh Sagone, dkk (2016) juga menjelaskan bahwa semakin tinggi resiliensi maka semakin dapat memilih konteks yang sesuai dengan kebutuhan pribadi, untuk melihat diri mereka tumbuh dan berkembang serta menganggap diri mereka puas dan bahagia.

\section{Hubungan resiliensi dengan kualitas hidup}

Hasil penelitian menunjukkan ada hubungan antara resiliensi dengan kualitas hidup dimana pasien penyakit ginjal kronis yang menjalani hemodialisis dengan resiliensi sedang sebanyak 5 orang responden memiliki kualitas hidup yang cukup dan 3 orang

\section{DAFTAR PUSTAKA}

Andaryati, A. (2018). Terapi kelompok dukungan untuk meningkatkan resiliensi pasien gagal ginjal kronik yang menjalani hemodialisa (Doctoral dissertation, Universitas Islam Indonesia). memiliki kualitas hidup yang kurang. Di sisi lain, resiliensi pasien penyakit ginjal kronis yang menjalani hemodialisis dengan resiliensi tinggi sebanyak 22 orang memiliki kualitas hidup baik, 68 orang memiliki kualitas hidup cukup dan 10 orang memiliki kualitas hidup yang kurang. Sedangkan untuk resiliensi yang sangat tinggi sebanyak 3 orang memiliki kualitas hidup yang baik dan 4 orang memiliki kualitas hidup yang cukup.

Hasil penelitian ini sejalan dengan penelitian yang dilakukan oleh Paramitha (2016) yang menyatakan bahwa adanya hubungan yang kuat dan memiliki arah yang positif antara tingkat resiliensi dan kualitas hidup pasien penyakit kronis. Pendapat Paramitha (2016) didukung oleh penelitian Aziza (2016) yang mengatakan bahwasetiap manusia memiliki kesulitan namun manusia memiliki ketahanan untuk bangkit dan melanjutkan hidup. Adanya resiliensi pada individu dapat membuat individu menjadi optimis, bangkit dan berpikir positif. Individu dengan resiliensi tinggi akan berusaha mencari jalan keluar dengan terus berusaha untuk sembuh dan menjalani pengobatan sehingga pada akhirnya resiliensi dapat meningkatkan kualitas hidup pasien gagal ginjal kronis yang menjalani hemodialisis.

\section{KESIMPULAN}

Kesimpulan penelitian ini adalah pasien peyakit ginjal kronis yang menjalani hemodialisis di Rumah Sakit Khusus Ginjal Rasyida mayoritas memiliki resiliensi yang tinggi, memiliki kualitas hidup yang cukup dan ada hubungan resiliensi dengan kualitas hidup pasien penyakit ginjal kronis yang menjalani hemodialisis di Rumah Sakit Khusus Ginjal Rasyida.

Hasil penelitian ini menunjukkan bahwa terdapat hubungan yang signifikan maka peneliti menyarankan agar penelitian selanjutnya melakukan penelitian tentang faktor-faktor yang mempengaruhi resiliensi dan kualitas hidup pasien gagal ginjal kronis yang menjalani hemodialisis.

Arosa, F. A. (2014). Hubungan tingkat pengetahuan keluarga tentang Hemodialisa dengan tingkat kecemasan keluarga Yang anggota keluarganya menjalani terapi Hemodialisa (Doctoral dissertation, Riau University). 
Aziza, Aprilia Indra. (2016). Hubungan Antara Dukungan Sosial dan Resiliensi dengan Kualitas Hidup Pasien Kanker Serviks di RSUD Dr. Soebandi Jember. Skripsi. Bagian Epidemiologi dan Biostatistika Kependudukan. Jember. Diakses pada tanggal 15 Januari 2020

Duncan, J., Bowden, C., \& Smith, A. B. (2005). Early childhood centres and family resilience. Ministry of Social Development.

Grief, A. D., \& Richardson, G. (2005). Mathematical modelling of magnetically targeted drug delivery. Journal of magnetism and magnetic materials, 293(1), 455-463.

Halawati, D. F. A., \& Kusuma, H. (2017). GAMBARAN RESILIENSI KELUARGA PASIEN PENYAKIT GINJAL KRONIK YANG MENJALANI HEMODIALISIS. Jurnal Perawat Indonesia, 1(1), 32-39.

Ibrahim, H. N., Foley, R., Tan, L., Rogers, T., Bailey, R. F., Guo, H., ... \& Matas, A. J. (2009). Long-term consequences of kidney donation. New England Journal of Medicine, 360(5), 459-469.

Iliescu, A. Cotoi, (2013). Patient's Adaptation Difficulties to the Hospital Environment. Nurse's Part in That Transition, Craiova : General Nursing Department, Faculty of Nursing and Midwives, University of Medicine and Pharmacy

Nurhasanah, N. (2017). The analysis of causes of divorce by wives. COUNS-EDU: The International Journal of Counseling and Education, 2(4), 192-200.

Oktaviana, R. (2010). Hubungan Antara Dukungan Sosial Dengan Depresi Pada Pasien Gagal Ginjal Yang Menjalani Hemodialisis. Psyche, 4(2).

Pane, J. P. (2014). Hubungan antara Koping dengan Resiliensi pada pasien Gagal Ginjal Kronik yang menjalani Hemodialisis di Rumah Sakit Umum Pusat Haji Adam Malik Medan (Master's thesis).

Paramitha, I. A. P., \& Susilawati, L. K. P. A. (2016). Resiliensi perempuan janda nyerod yang pernah mulih deha. Jurnal Psikologi Udayana, 3(3), 466-478.
Rachmawati, B. D., Listiyandini, R. A., \&Rahmatika, R. (2019). Resiliensi psikologis dan pengaruhnya terhadap kualitas hidup terkait kesehatan pada remaja di panti asuhan. ANALITIKA, 11(1), 21-30.

Ramadhan, H. F., Hermansyah, Y., Wisudanti, D. D., \& Suryono, S. (2018). Hemodialysis Effect on Systolic Left Ventricular Function in Stage V Chronic Kidney Disease Patients. JOURNAL AMS, 4(3), 128-132.

Sagala, D. S. P. (2015). Analisa Faktor-Faktor Yang Mempengaruhi Kualitas Hidup Pasien Gagal Ginjal Kronik Yang Menjalani Hemodialisa Di Rumah Sakit Umum Pusat Haji Adam Malik Medan. Jurnal Ilmiah Keperawatan Imelda, 1(1), 8-16.

Sagone, E., \& De Caroli, M. E. (2014). Relationships between psychological well-being and resilience in middle and late adolescents. Procedia-Social and Behavioral Sciences, 141, 881-887

Sarafino, E. P. (2006). Health psychologybiopsychosocial interactions. 2002.

Smeltzer, S. C., \& Bare, B. G. (2010). Brunner \& Suddarth's textbook of medical-surgical nursing. Philadelphia: JB Lippincott.

Sukadiyanto, S. (2010). Stress dan cara menguranginya. Cakrawala Pendidikan, (1), 82176.

Triwahyuni, P. (2012). Hubungan Antara Resiliensi dengan Stres pada Pasien Penyakit Kronis di Rumah Sakit Advent Bandung: Universitas Advent Indonesia. Skripsi

Utami, C. T. (2017). Self-Efficacy dan Resiliensi: Sebuah Tinjauan Meta-Analisis. Buletin Psikologi, 25(1), 54-65.

Wagnild, G. M. (2010). Discovering your resilience core. Resiliencescale. com, 1-4.

World Health Organization. 2010. WHO Quality of LifeBREF (WHOQOL-BREF). http://www.who.int/ substance abuse/research tools/whoqolbref/ en/. Tanggal 31 Oktober 2016. Jam 23.58 WIT.

Wijayani, M.,R.(2008). Gambaran Resiliensi Pada Muslimah Dewasa Yang Menggunakan Cadar. Jakarta: FPSI UI. Skripsi 